\title{
Electrically Open Reed Device
}

National Cancer Institute

\section{Source}

National Cancer Institute. Electrically Open Reed Device. NCI Thesaurus. Code C50136.

A switch device consisting of thin, flexible, magnetically controlled contacts enclosed in a sealed and evacuated enclosure. 